\title{
Anne Mounic, L'Esprit du récit ou la chair du devenir. Éthique et création littéraire
}

\section{Andrea Schellino}

\section{(2) OpenEdition}

1 Journals

\section{Edizione digitale}

URL: http://journals.openedition.org/studifrancesi/2329

DOI: 10.4000/studifrancesi.2329

ISSN: 2421-5856

\section{Editore}

Rosenberg \& Sellier

\section{Edizione cartacea}

Data di pubblicazione: 1 aprile 2014

Paginazione: 202-203

ISSN: 0039-2944

\section{Notizia bibliografica digitale}

Andrea Schellino, "Anne Mounic, L'Esprit du récit ou la chair du devenir. Éthique et création littéraire »,

Studi Francesi [Online], 172 (LVIII | I) | 2014, online dal 01 avril 2014, consultato il 18 septembre 2020.

URL : http://journals.openedition.org/studifrancesi/2329; DOI : https://doi.org/10.4000/studifrancesi. 2329

Questo documento è stato generato automaticamente il 18 settembre 2020.

\section{(c)}

Studi Francesi è distribuita con Licenza Creative Commons Attribuzione - Non commerciale - Non opere derivate 4.0 Internazionale. 


\title{
Anne Mounic, L'Esprit du récit ou la chair du devenir. Éthique et création littéraire
}

\author{
Andrea Schellino
}

\section{NOTIZIA}

ANNE MOUNIC, L'Esprit du récit ou la chair du devenir. Éthique et création littéraire, Paris, Champion, 2013, pp. 586.

1 Con L'Esprit du récit ou la chair du devenir, Anne mounic prosegue la propria riflessione sulla nozione di "esprit du récit", da cui recentemente sono nati Jacob ou l'être du possible (2009) e Monde terrible où naître. La voix singulière face à l'Histoire (2011). Questo concetto, mutuato da Imre Kertész, è in grado per l'A. di garantire il necessario legame di continuità della creazione letteraria e artistica nel corso del tempo: «L'esprit du récit, c'est donc le lien de continuité que le sujet établit quand, libre dans son choix, il étreint l'angoisse du possible, et s'efforce sans cesse de ressaisir dans la substance de l'expérience singulière ce que l'esprit dans le langage tendrait à objectiver par trop, jusqu'à nier la réalité physique, la réalité sensible» (p. 42). Questo ambizioso tentativo di una nuova fondazione estetica ed esistenziale della poesia si basa sulla presa d'atto delle numerose rotture che hanno sconvolto la vita dello spirito dal xviII secolo, in particolare l'opposizione tra religioso e non-religioso. Il poeta, di fronte a questi interrogativi, non sceglie, ma «s'identifie à la vie pour la manifester en sa vérité singulière et éphémère» (p. 14). La libertà è il campo del possibile, del cominciamento.

2 L"esprit du récit" si sviluppa nella continuità dell'animo umano, prolungandolo, e «manifeste l'unité de l'être au sein du devenir, unité en perpétuelle métamorphose, orientée vers l'infini et l'ouvert» (p. 15). Facendosi carico dell'origine e della catena della memoria, apre all'avvenire, all'ambito delle possibilità e delle scelte. Secondo l'A., che si pone sulla scia del pensiero di Kierkegaard e di Levinas, la concezione che si 
profila in tal modo rifiuta il dualismo tra pensiero e linguaggio, e colloca l'Io alla soglia della manifestazione del $\mathrm{Tu}$. Contro il determinismo del passato, «l'acte individuel constitue le miracle. Le récit se tourne vers l'avenir, vers le possible. Il s'inscrit donc dans l'infini, dans l'excès par rapport au monde fini de la logique, qui fonde la connaissance» (p. 19).

Per Anne Mounic, il linguaggio costituisce lo spirito in quanto luogo di sintesi tra anima e corpo; esso ci fonda e ci supera. La parola, infatti, non è un simbolo disincarnato, ma è realtà sensibile, presenza. In questo senso dalla scrittura dei poeti - destinati a fare $\mathrm{i}$ conti con la trascendenza assoluta e la «durée», che provocano la morte della «voix singulière» - emana un autentico umanismo, un «humanisme de chair» (p. 32).

Il volume è diviso in tre parti. Nella prima, Conte, continuité, l'A. considera il racconto come continuità e la possibilità come rottura, a partire da alcuni testi di Shakespeare. Analizzando una folta seria di testi poetici e romanzeschi, e la relazione $\mathrm{Je} / \mathrm{Tu}$ nella poesia di Claude Vigée, l'A. esplora inoltre la nozione di scelta etica e poetica, e la fede degli scrittori. La seconda parte (Figures, métamorphoses du sensible) esamina alcune figure emblematiche della letteratura che permettono di assumere la continuità esistenziale del racconto: «Les figures donnent leurs visages aux instants en manifestant l'humain grâce au processus de reconnaissance qu'elles engendrent» (p. 209). La terza e ultima parte (Figures, langage et devenir) mette in relazione il linguaggio e il divenire dal punto di vista del cominciamento, tramite lo studio della figura del serpente in Martin Buber, Robert Graves e R.K. Narayan. L'A. affronta così la questione della somiglianza, che implica alcune fondamentali dissociazioni: «Convertissant du Je au Tu, dans l'œuvre, notre essentielle passivité en liberté, nous plongeons, en deçà du bien et du mal, en deçà du domaine du jugement, dans l'ambivalence existentielle originelle, là où s'articule la genèse de la conscience réflexive, au cœur de la réciprocité» (p. 378). In conclusione (ma «sans vouloir conclure»), l'A. ribadisce la centralità del pensiero poetico e - citando Benjamin, Fondane e Baudelaire - la dignità del linguaggio e della «chair du devenir» davanti agli abissi dell'esistenza. 